\title{
REPENSAR A MODERNIDADE É REPENSAR A EUROPA: UMA LEITURA POSSÍVEL DE $A$ VOZ DA TERRA, DE MIGUEL REAL
}

Paolo La Valle ${ }^{1}$

Resumo: No romance $A$ voz, da terra (2005), Miguel Real põe em evidência o lado mais violento das políticas do Marquês de Pombal. Uma leitura radicalmente diferente do mito que ao longo dos anos se tem constituído sobre a figura do ministro Sebastião José de Carvalho e Melo. O romance de Miguel Real compreende uma reflexão sobre a modernidade não só em Portugal, mas também na Europa. Em $A$ voz da terra é possível, dessa forma, ler uma crítica dos processos contemporâneos que levaram Portugal a entrar na nova ordem econômica europeia.

Palavras-chave: Miguel Real; Marquês de Pombal; modernidade, mito.

\section{TO RETHINK MODERNITY IS TO RETHINK EUROPE: A POSSIBLE READING OF MIGUEL REAL'S $A$ VOZ DA TERRA}

\begin{abstract}
Miguel Real, in his novel $A$ voz da terra (2005), draws attention to the more violent aspect of the Marquis of Pombal's politics. This reading is radically different from the myth that in the years have constructed around the Marquis, who is usually construed as a figure of Enlightened rationalisation and Europeanisation of Portugal. This article argues that the novel of Miguel Real involves a reflection about modernity not only in Portugal, but also in Europe in general. $A$ voz da terra could be read as a critique of the contemporary processes that brought Portugal to enter into the new European economic order.
\end{abstract}

Keywords: Miguel Real, Marquis of Pombal, modernity, myth.

\section{Introdução}

No final do ano de 2005, na ocasião dos 250 anos do Terremoto de 1755, o mundo editorial foi protagonizado pela publicação de vários livros sobre esse tema. A literatura tem obviamente um papel importante na produção e na divulgação das narrativas ligadas ao evento. Aos romances de Hélia Correia, Lilias Fraser (2001) e de Luís Rosa, O Terramoto de Lisboa e a Invenção do Mundo (2004), juntam-se, em 2005, os de Júlia Nery, Lisboa, Terramoto de 1755, O segredo perdido, de José Braga Gonçalves, O maçon de Viena, de Pedro Almeida Vieira, O segredo do Mistério Divino e o de Miguel Real, $A$ Voz da terra.

É o mesmo Miguel Real que, além de contribuir para a reconstrução da literatura

1 Estudante do programa de doutorado Letterature classiche, moderne, comparate e postcoloniali da Università di Bologna. 
contemporânea sobre o tema nas páginas do "Jornal de Letras, Artes e Ideias", escreve um romance que se posiciona de forma crítica face à memória do Grande Terremoto na cultura portuguesa, particularmente em relação à memória do ministro Sebastião José de Carvalho e Melo, o futuro Marquês de Pombal. A obra de Miguel Real desconstrói a figura do ministro, mostrando como o seu exercício de poder, inspirado no iluminismo europeu, é na realidade caracterizado por uma tensão centralizadora e violenta.

\section{A ruptura do Grande Terramoto}

No ano de 2005, também não faltam publicações historiográficas sobre o Terremoto. Entre esses livros, destaca-se o volume O Grande Terramoto de Lisboa: ficar diferente (BUESCO, CORDEIRO, 2005), que procura mostrar como as reações face à catástrofe são acompanhadas por mudanças no nível cultural que conectam o panorama português ao contexto europeu e ao brasileiro.

Talvez o livro mais importante sob esse ponto de vista seja O pequeno livro do Grande Terramoto (2005), escrito por Rui Tavares, onde o processo de narração do Terremoto de Lisboa é descrito mediante a comparação com outros eventos catastróficos. É a partir dessas comparações que se torna possível evidenciar as operações de mitificação que no curso da história envolvem o evento.

O próprio título do livro contém a ironia do contraste entre a grandeza do Terramoto e a pequenez do livro. Porém, a ironia de Tavares carrega um significado político que está ligado a uma ideia da história, que por sua vez legitima uma narração específica do acontecimento. Dessa forma, a análise do ensaio reconstrói o contexto em que a narração do Terremoto se forma, dirigida pelo ministro Sebastião José de Carvalho e Melo, o futuro Marquês de Pombal.

$\mathrm{Na}$ realidade, o Grande Terremoto representa um momento de ruptura com a forma teológica impulsionada pela Igreja para explicar fenômenos naturais. Trata-se de um dos principais feitos do ministro Carvalho e Melo, que, na sua luta conduzida contra da Companhia de Jesus, consegue impor outra leitura do evento que não seja a de uma punição de Deus contra os pecados de uma Lisboa que, como uma Gomorra moderna, deveria voltar a seguir os dogmas da Igreja para se libertar da ira divina. Baseando-se nos documentos da época, e em particular no texto do Diário dos sucesso de Lisboa desde o 
Terramoto até o Exterminio dos Jesuitas, escrito por António Pereira de Figueiredo, Rui Tavares mostra como é que se ativa a construção de um processo de memória histórica que legitima e reforça a posição do ministro Carvalho e Melo. A construção de uma narrativa legitimadora é também um dos elementos evidenciados por Miguel Real, que, no seu ensaio O Marquês de Pombal e a cultura portuguesa, sublinha a importância de três livros "diretamente orientados pelo Marquês: a Relação Abreviada (1757), a Dedução Cronológica e Analítica (1768) e o Compêndio Histórico do Estado da Universidade de Coimbra (1771)" (REAL, 2005b, p. 9).

Por outro lado, na elaboração do mito do Terremoto participam também alguns protagonistas da cultura europeia, entre os quais destacam-se Leibniz, Pope e Voltaire, que direcionam o processo de construção da reflexão sobre o acontecimento. A construção das narrativas sobre o acontecimento afasta-se de uma possível explicação teológica, para ser incluída na perspectiva iluminista que dominava a vida intelectual na Europa do século XVIII.

Mas é também no processo de reconstrução da cidade de Lisboa que o Terramoto pode ser definido como "o primeiro desastre moderno" (DYNES, 2005, p. 34): a reconstrução da capital portuguesa, a que Rui Tavares chama de "haussmanização" (TAVARES, 2005, p. 45), correspondeu a um processo de mudanças do Estado em que é possível analisar os traços materiais do processo "civilizador" impulsado pelo ministro.

\section{Uma cidade longe da Europa}

A Lisboa anterior ao Terramoto descrita por Miguel Real é vista pelos olhos de Julinho, o protagonista do romance, que volta a Portugal depois de um longo período de ausência, tendo ele ficado durante trinta anos em Pernambuco. A descrição da cidade é caótica, uma mistura contínua entre uma descrição física do que Julinho vê e os contos sobre a situação política feitos pelos "Peixotinhos", ou seja, os irmãos João Maria e José Maria Peixoto: antigos amigos de Julinho, companheiros de aventura durante a adolescência e agora colaboradores do ministro Sebastião José de Carvalho e Melo.

Mas é a própria Lisboa que parece ser constituída em níveis diferentes: a cidade apresenta uma enorme variedade de estímulos, e situações ligadas ao mundo do trabalho e à pobreza se contrapõem à cidade mais nobre, onde ficam os palácios e os bairros mais ricos. Julinho pertence à segunda destas cidades, embora o seu caráter seja mais aberto do 
que o dos seus amigos, atados aos privilégios da sua classe social. Portanto, o seu primeiro olhar face à cidade fixa-se nessa parte mais rica, ao contrário do olhar do narrador, que, antes de descrever o que Julinho procura ver, põe em evidência os sons ao redor da personagem e que não são ouvidos por ela:

o marioleiro que trazia Julinho para o cais ia-lhe perguntando de que índia viera, ele também queria ir para lá, catar ouro ou carregar canela, mas Julinho não o ouvia, nem o eco estralejado das ondas no molhe, nem o vozear agudo dos outros matalotes carregando os arcões desembarcados do São Bartolomeu, nem o clamor aflautado dos fidalgos que seguiam sob o dossel aveludado de carin do bergantim que à sua frente fendia as ondas do Tejo, nem os estalos compassados da pequena vela sobre a sua cabeça; Julinho só tinha olhos para a vista de Lisboa, a cidade de Santo António, o ondeado das sete colinas cobertas de casario e de igrejas, coroadas pelo castelo e cintadas por olivais e pomares, a mole do palácio dos Cortes Reais e dos Braganças captando a vista no extremo da baía, aberta pela quinta régia de Belém, oposta aos pináculos da Sé e da grossa alvenaria de S. Vicente. (REAL, 2005a, p. 13).

A distância entre o narrador e Julinho não é sempre tão marcada. $\mathrm{O}$ que o narrador descreve sem qualquer tipo de julgamento é percebido por Julinho com um certo atordoamento ao ver como Lisboa está tão desligada do seu papel de "cabeça de império" (REAL, 2005, p. 17). Lisboa é caótica e desordenada, cheia de pessoas, de sons e de identidades diferentes. No plano urbanístico, essa desordem é evidente: a cidade é "uma rede embaraçada vermelha e branca, desnivelada, ondulante, sinuosa, aqui e além quebrada abruptamente pela bocara de madeira de um telheiro ruído" (REAL, 2005a, p. 18).

A presença dos escravos marca com força as primeiras descrições da cidade. Os escravos trabalham no porto, pedem dinheiro na rua e obedecem às ordens dos Peixotinhos e dos seus familiares. É nesse assunto que se torna evidente a diferença entre Julinho e os seus camaradas. O próprio Julinho tem um escravo, Florentino, mas a relação entre eles é de absoluta confiança e respeito. As suas contínuas referências ao Padre Almeida Vieira são um sinal das suas ideias liberais em relação ao contexto português da época, em que tais ideias não têm legitimidade. A única posição liberal legítima parece ser a do futuro Marquês de Pombal, descrita pelas palavras dos Peixotinhos:

estou a gostar desse Ministro, tem a sensatez de libertar os escravos em Portugal, mas de não tocar nos do Brasil, sem os 
escravos do açúcar e do ouro o Brasil morre, só os pretos aguentam aqueles trabalhos. (REAL, 2005a, p. 26)

O liberalismo do Ministro é dessa forma limitado, especialmente do ponto de vista de Julinho: aberto às influências europeias e iluministas sobre o direito à liberdade pessoal, mas desde que esse direito não se contraponha à riqueza económica oriunda das colônias. Esse liberalismo limitado encontra na resistência da aristocracia o verdadeiro bloqueio às políticas do Ministro, como explica João Maria, um dos dois Peixotinhos: "não há manufactura que não rebente sob tanta madraçaria e corrupção, não há progresso que não estale contra o muro de superstição de mulheres e cleria, que d. João V privilegiava" (REAL, 2005a, p. 36).

O tema do progresso torna-se central: todos os obstáculos às políticas do ministro têm como resultado o de afastar Portugal do contexto europeu e pô-lo numa posição de inferioridade em relação aos outros impérios. O ministro Carvalho e Melo é a pessoa que mais repara nesse desequilíbrio devido à presença da nobreza e dos jesuítas: "há duzentos anos que Portugal deixou de contar para Europa" (REAL, 2005a, p. 109). O Portugal anterior ao Terramoto parece estar amarrado a um atraso que só poderia ser desmantelado por uma grande obra de renovação.

Os irmãos Peixotinhos representam as vozes de quem na altura via no ministro de Carvalho e Mello a personagem capaz de trazer um progresso contra a classe aristocrática e o papel da Igreja na sociedade. Porém, discutir sobre outros assuntos, como a possibilidade do fim da escravidão nas colônias ou a independência destas, já não é considerado parte da utopia do progresso.

O suposto atraso de Portugal tem, portanto, um papel decisivo na construção do mito do Marquês de Pombal como inovador e construtor iluminista. Ele é o herói, o Dom Sebastião moderno, capaz de elevar Portugal ao nível dos outros impérios.

\section{O mito do Marquês de Pombal}

O investigador italiano Furio Jesi chama de "mito tecnicizzato" à distorção de uma narrativa para justificar e legitimar uma ação política². O mito da cruzada contra os

2 A respeito do "mito" em Furio Jesi, verificar o livro de Enrico Manera, Furio Jesi: Mito, memoria, violeña. (MANERA, 2012). 
comunistas, por exemplo, era utilizado por Franco para legitimar e manter a ordem do regime franquista espanhol, e o mito dos "italiani brava gente" era utilizado para encobrir as violências italianas nas colônias. Do mesmo modo, o do Marquês de Pombal pode ser analisado como um mito que tem justificado, em diversos momentos, uma certa ordem social.

Segundo as análises de José Eduardo Franco e Annabela Rita, a partir do século XIX, o Marquês de Pombal foi elevado "ao estatuto de herói da modernidade portuguesa e precursor de valores democráticos em função da sua política regalista e anti-jesuíta e subjugadora da poderosa nobreza tradicional ao poder absoluto do Estado" (FRANCO, RITA, 2004, p. 33). Essa visão tem o seu apogeu em 1882, na ocasião do centenário da morte do Marquês, por parte da Maçonaria, que faz dele um autêntico "herói laico":

esta marca ideológica conduziu a classificações historicamente erróneas e, algumas delas, anacrónicas, da obra política protagonizada por Carvalho e Melo. Os epítetos que foram atribuídos a este político do absolutismo são bem ilustrativos disto mesmo, como são os casos mais impressionantes da sua classificação e exaltação como "liberal" ou precursor da Revolução Liberal, ou de "primeiro grande revolucionário português", de "um homo novus", um "quase plebeu", que tinha cedido ao poder à custa do seu mérito. (FRANCO, RITA, 2004, p. 53-55)

Os fundamentos do mito do Marquês de Pombal encontram uma base em fatos reais: o ministro Carvalho e Melo é de fato o protagonista da luta contra os jesuítas e contra os costumes religiosos mais tradicionalistas, sendo realmente o protagonista da reconstrução da cidade de Lisboa através da planificação de uma nova Baixa, não labiríntica como a anterior, mas construída com um esquema geométrico e ordenado, graças à supervisão dos arquitectos Manuel de Maia, Eugénio dos Santos e Carlos Mandel. Ao mesmo tempo, depois do Terremoto, é o ministro Carvalho e Melo que realiza reformas que têm diversas ligações com o clima do iluminismo europeu, no campo económico, jurídico, e sobretudo escolástico, pondo a escola sob o controle do Estado, e não dos jesuítas.

A figura do Marquês de Pombal vincula-se, então, ao contexto do desenvolvimento do Estado moderno, em que a instituição estatal é a base legitimadora e produtora da ordem social, e, assim, glorificar sua a figura é glorificar a mesma nação portuguesa. Também por isso o mito de Pombal chega até aos dias de hoje, na medida em que, na 
grande produção literária sobre o Terremoto no final de 2005, Marquês de Pombal ainda é descrito como um "gênio" e a Lisboa reconstruída depois do Terramoto vem a ser "a grande criação do Iluminismo"’3.

O que fica oculto, ou justificado pelo processo de mitificação, é a violência com que as políticas do ministro são realizadas, sendo este um dos elementos em que se concentra o romance de Miguel Real. É importante sublinhar que essa violência é, sobretudo, contra os jesuítas, aos quais o ministro Carvalho e Melo chama de um "autêntico Estado dentro do Estado" (REAL, 2005a, p. 110). Mas é também uma violência geral que impõe um modelo de progresso que implica o controle da população e a supressão de qualquer outra voz. Inicialmente, a violência do ministro explicita-se pela repressão da revolta do Porto, conduzida, segundo o ministro, por "caterva de borrachos, prostitutas, soldados, desertores, escravos, vadios, enfim levantaram a ralé da cidade e ocuparam a Ribeira, com miúdos e grávidas à frente, gritando que o vinho é do povo" (REAL, 2005a, p. 110). Entretanto, a violência é exercida sobretudo em Lisboa, nos meses posteriores ao Terremoto, quando o ministro incumbe o controle da cidade ao Porão Escorço, uma personagem que Julinho já conhece pelas suas violências contra os negros no Brasil.

Já antes do Terremoto, Porão Escorço é encarregado pela Igreja de reprimir o "candomblé", um ritual religioso dos negros escravos em Lisboa, importado do Brasil, em que, com uma dança, procura-se caçar o demônio. Graças às políticas do Marquês, o papel de Porão Escorço é justificado pelo Estado e, portanto, glorificado aos olhos da cidade, que procura sair da emergência: "o mercenário mais odiado de Pernambuco no tempo da juventude de Julinho, atravessava Lisboa montado a cavalo, aplaudido e louvado como um herói” (REAL, 2005a, p. 176).

É também pela violência justificada por meio de instrumentos jurídicos que se manifesta a política centralizadora do Marquês de Pombal, ao acusar a família Távora de ter realizado um complot contra o rei. Na realidade, a conjura só resulta ser uma desculpa para acusar e atacar a nobreza, pondo limites ao seu poder. É o primeiro sinal do despertar da "voz dos homens": as decisões do Marquês são poderosas e ao mesmo tempo terríveis, e são comparadas com um novo Terremoto:

despertara a Voz dos Homens, que aterrorizaria Lisboa, saída dos

3 Esse é o título de um artigo de José Augusto França no Jornal de Letras, Artes e Ideias. 
tormentos da Voz da Terra, e que, em nome da justiça, findaria com o mais hediondo morticínio ordenado pelo Estado português, a crudelíssima execução da família dos Távoras. (REAL, 2005a, p. 204)

A violência liga-se, então, ao projeto de construção de um novo Estado, na medida em que, segundo as palavras de Julinho, "as quatro principais ruas da nova Lisboa tinham sido construídas sobre a carne e o sangue das duas mais eminentes famílias do antigo Portugal.” (REAL, 2005a, p. 224-225).

Porão Descorço torna-se a mão armada do ministro Carvalho e Melo e é chamado de "terramoto dos homens", ou seja, o ataque contra a Companhia de Jesus. Numa semana, detém mais de 1000 pessoas que se supõe estarem ligadas de alguma maneira à conjura e, sendo tais detenções absolutamente arbitrárias, é o ministro quem manda criar provas, "solidificando-as pelo terror e pela tortura" (REAL, 2005a, p. 239).

Não é só a violência física que preocupa Julinho, pois ele repara que há uma violência no próprio modelo de progresso que o ministro está a impulsar. Julinho vê, nesse controle despótico, uma nova forma de governo, que não é menos perigosa que a antiga. O que a diferencia é apresentar-se como uma novidade, no entanto, sem provocar verdadeiras mudanças em relação ao tema da tolerância e às injustiças que já existem.

Essa imagem do Marquês de Pombal, desconstruída face ao seu mito, relaciona-se com a definição de Kenneth Maxwell, que qualifica o Marquês de "paradoxo do iluminismo". Maxwell analisa as políticas do Marquês, principalmente no que se refere ao desenvolvimento do comércio português, e sublinha dois pólos da questão: o despotismo do Marquês frente às suas políticas iluministas (MAXWELL, 1995, p. 2) e "o conflito entre intenções despóticas e objetivos iluminados” (MAXWELL, 1995, p. 38).

No entanto, resta saber se o mito do Marquês de Pombal não está ligado a uma outra narrativa mítica, a da modernidade europeia como momento de emancipação da humanidade, em nome de uma racionalidade técnica e científica a caminho do progresso e, por isso, privada de contradições.

\section{Uma modernidade exemplar?}

No romance de Miguel Real, a mesma narrativa da modernidade deve ser problematizada pela figura do Marquês de Pombal, que representa a transição para um 
novo Portugal, que quer se livrar da nobreza e do poder dos jesuítas para se equivaler aos outros estados europeus. No entanto, a luta do Ministro Carvalho e Melo não é isenta de ambiguidades: o contraste entre o velho e o novo sistema político é caracterizado por várias tensões que decorrem dos poderes existentes e o Ministro não tem sempre a possibilidade de escolher o que é melhor para o seu projeto político.

Esse mecanismo é evidenciado no colóquio entre o Ministro e Julinho sobre a possibilidade da independência do Pernambuco: Julinho sabe perfeitamente que deve pesar suas palavras, com o risco de ser acusado de lesa-majestade, e por isso passa a utilizar argumentos que o Ministro possa apreciar, sendo próximas de seus projetos: "queremos comércio livre [...] que as leis do novo Estado sejam as portuguesas, mas a economia europeia" (REAL, 2005a, p. 112). Ao mesmo tempo, o Ministro sabe que não pode haver erros na sua estratégia, visto que, no contexto político anterior ao Terremoto, ele próprio correu o risco de ser condenado como traidor do império:

a proposta de Julinho ganhara a simpatia do Ministro, mas dificilmente os membros do Conselho Ultramarino, órgão que aconselhava el-rei em matéria imperial, aceitariam a proposta, considerá-la-iam um simples negócio burguês do Ministro, troca de soberania por dinheiro. [...] Era preciso pensar. (REAL, 2005a, p. 114)

Esse quadro muda depois do Terremoto e Julinho repara logo nisso: com o Terremoto, o ministro parece esquecer a proposta de independência do Pernambuco, já que a coisa mais importante é a reconstrução de Lisboa e, em geral, do estado português. $\mathrm{O}$ ministro tem agora mais espaço político para acelerar suas reformas, na tentativa de fazer de Portugal um estado europeu, com um processo que acentua as preocupações do Julinho:

Se em outros países, o novo e o velho se sobrepunham em acumulações sucessivas, que as gerações iam incorporando pacificamente, em Portugal o novo e o velho teciam-se de sangue, de dissidência, de violência, de ódio mútuo, de revolta e reacção, de mútua tentativa de esmagamento. (REAL, 2005a, p. 225)

Essa perspectiva parece ser a única possível para o Portugal do futuro e o ministro Carvalho e Melo representa-a perfeitamente. Através dos seus projetos políticos e das suas modalidades de atuação, é possível criar uma ponte com o Portugal contemporâneo.

Essa relação torna-se mais evidente em outro livro, um ensaio historiográfico, 
publicado no mesmo ano por Miguel Real. O autor toma o cuidado de não tomar partido nas dicotomias simplificadas, ou seja, entre o Marquês de Pombal e os jesuítas, ou entre o atraso português e o espírito vanguardista. Real analisa a modalidade narrativa e retórica do Marquês para representar um Portugal atrasado, abaixo do nível da Europa do seu tempo, "transformando a imagem de decadência no operador mental mais constante e mais influente da cultura portuguesa contemporânea" (REAL, 2005b, p. 9). A partir desse impulso, a justificação do Marquês de Pombal para as rupturas com a ordem política decorre da tentativa de aproximar Portugal da Europa central: atuar "em nome da Europa" (REAL, 2005b, p. 11) torna-se, assim, o eixo central da política do Marquês. "Em nome da Europa", são expulsos os jesuítas e a família Távora é perseguida. "Em nome da Europa", começa uma política de estatização dos tribunais, uma centralização da economia e até das artes e das letras, concluindo-se dessa maneira o ensaio. Eis o começo de uma disposição que, segundo Real, durará “até à nossa adesão à Comunidade Económica Europeia em 1980” (REAL, 2005b, p. 13).

A entrada de Portugal na Comunidade Europeia assume, desse modo, um papel de ruptura face à cultura portuguesa. Essa leitura é ainda mais clara quando comparada com outro ensaio de Miguel Real, Eduardo Lourenço e a cultura portuguesa (REAL, 2008). A questão cultural e a relação entre Portugal e a Europa nos escritos de Eduardo Lourenço formam o tema do primeiro capítulo do ensaio, onde Real evidencia a tentativa, por parte de Lourenço, de demonstrar a relação entre a cultura portuguesa e a cultura europeia em duas fases diferente do seu percurso: a primeira, de 1949 até 1978, e a segunda, de 1978 até 1997. Segundo Real, a primeira fase da "heterodoxia" de Lourenço acaba em 1978:

com a pre-adesão de Portugal à Comunidade Económica Europeia, em 1980, e a adesão plena em 1986, bem como a consolidação definitiva do regime democrático, as teses da heterodoxia perdem alguma da sua intensidade devido à inexistência de ortodoxias dogmáticas no comando do sistema político e na representação imagética da cultura portuguesa. As duas antigas colunas da ortodoxia - o dogmatismo estruturalmente anquilosado da Igreja Católica como suporte ideológico do Estado sofrera o choque conciliar do Vaticano II, renovando-se, bem como o Partido Comunista Português no seio do regime democrático com o estatuto de apenas mas um entre vários partidos - vêem, assim, perder a sua antiga predominância, atravessados pelo espírito do debate libre e da concorrência tolerante entre as instituições soprados da Europa ao longo da 
década 1980. (REAL, 2008, p. 80)

A adesão à CEE torna-se num momento decisivo para a mudança do pensamento sobre a modernidade europeia, estando esta associada à construção do mito do ocidente, que agora está a chegar ao seu fim. A cultura portuguesa tem de ser pensada de outra forma em relação à precedente, isto é, à do regime fascista. Se "heterodoxia", durante o regime fascista, era mostrar uma identidade cultural portuguesa europeia, agora "heterodoxia" é pôr em evidência que "a Europa se encontra num plano inclinado de decadência, preparando-se para o 'Grande sono’ do silêncio histórico” (REAL, 2008 p. 82), ser português dentro da nova Europa é, assim, assumir o papel de "repensar a Europa".

A falta de um pensamento crítico sobre a entrada de Portugal na Comunidade Europeia está no centro da atenção de Lourenço e de José Saramago, outro escritor fundamental para Miguel Real ${ }^{5}$, que em 1988 publica um romance que vai diretamente ao encontro desse tema: A jangada de pedra. Sobre a mesma relação entre Portugal e a Europa, é possível construir uma crítica que muitas vezes tem seduzido a cultura portuguesa, apesar da sua "exemplaridade duvidosa" (LOURENÇO, 1990, p. 31). O livro de Miguel Real permite investigar a mesma "exemplaridade duvidosa" da modernidade europeia.

Para propor essa leitura, convém referenciar o livro de Zygmunt Bauman, Modernity and the Holocaust, em que o autor desconstrói os esquemas clássicos com os quais o fenômeno do Holocausto é analisado: segundo a análise de Bauman, o extermínio dos judeus pelos nazistas não se caracterizaria por ser uma exceção na história da humanidade, mas sim uma consequência de elementos já presentes na modernidade.

O estado de exceção com que o Holocausto é habitualmente pensado tem como consequência "the self-healing of historical memory" (BAUMAN, 1989, p. X), ou seja, o afastamento das responsabilidades históricas, atribuindo-as a uma sociedade diferente e longe da nossa, com a qual não temos nenhuma relação. Desse modo, é possível analisar certas passagens que naquela época poderiam parecer "normais" e que legitimaram o extermínio dos judeus, numa sociedade construída segundo os critérios da "razão".

A análise de Bauman permite-nos ver no Holocausto não uma exceção, mas sim uma “janela” por onde é possível contemplar o fenômeno moderno total.

4 Esse é o título do parágrafo dedicado à segunda fase da beterodoxia de Eduardo Lourenço (REAL 2008, p. 84).

5 Veja-se o artigo de Miguel Real “A herança de José Saramago" (REAL, 2013). 
$\mathrm{Na}$ origem dessa sociedade guiada pela razão, o papel das elites torna-se um assunto central, que constitui outra contradição da modernidade: o fato da construção de um estatuto legislativo ser um papel de poucos "iluminados", que têm de impor regras morais à sociedade (BAUMAN, 1993).

Voltando à figura do Marquês de Pombal, se uma possível leitura desta pode ser a de questionar a sua proximidade com os ideais iluministas, outra possibilidade, advinda das sugestões de Bauman, é a de ler no Marquês algumas contradições do próprio projeto moderno.

A obra de Miguel Real permite pensar a modernidade como um momento ambíguo, em que a emancipação e o autoritarismo estão muito mais próximos do que possa parecer. Criticando, desta forma, a origem da relação entre Portugal e a Europa moderna, é possível encontrar similitudes com o contexto contemporâneo.

\section{Fé e ilusões}

A crítica da Europa enquanto União Europeia pode ser uma das formas de analisar o romance. A partir dessa perspectiva, é possível ler $A$ voz da terra como um romance com um "lado satírico, por vezes mesmo burlesco" (TAVARES, 2006, p. 42) e ressaltar as eventuais ligações do Marquês de Pombal com a sociedade contemporânea.

Porém, essa leitura é deixada a cargo do leitor: Miguel Real não chega a tomar posição de forma explícita, nem nas análises contidas nos seus ensaios, nem no seu romance: $A$ voz da terra não pode ser lido como um livro contra o projeto da união econômica europeia (uma das possíveis leituras do romance de Saramago), nem como um livro que fornece uma leitura estruturada de Portugal contemporâneo. Seja no romance, seja nas entrevistas e nos ensaios, Miguel Real interrompe suas narrações antes que qualquer posição se torne explícita.

O título de um dos últimos capítulos brinca com essa ambiguidade: a raiva de Julinho contra as políticas do ministro Carvalho e Melo explode no capítulo "Febre da Europa", em que Julinho declara aos Peixotinhos a sua vontade de sair de Lisboa e voltar a Pernambuco, apesar de ter participado das novas políticas comerciais impulsionadas pelo ministro. Mas o novo incentivo ao comércio apresenta-se como uma nova religião, para impor uma forma de gestão do estado que não admite alternativas e que continua sendo 


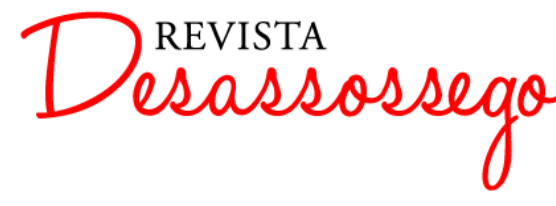

DESASSOSSEGO 12 | DEZ/2014 | ISSN 2175-3180

DOI: http://dx.doi.org/10.11606/issn.2175-3180.v6i12p5-19

caracterizada por prejuízos e injustiças, exatamente como antes:

Lisboa é uma cidade sitiada, ontem era a febre do Império da Fé, do Evangelho, hoje é a febre da Europa, do Progresso, do Comércio, da Industria, tudo é esmagado cruelmente em nome da nova missão de Portugal, ser europeu. [...] será que a adoração pelo Comércio e pela Indústria não vieram substituir a adoração pelas ordens religiosas, jesuítas e franciscanos? (REAL, 2005, p. 286).

Nas respostas de João Maria Peixoto a Julinho está resumido aquilo que será o mito do Marquês de Pombal:

com as reformas que o Ministro vai fazer, se o primeiro castigo não tivesse sido cruel, quase bárbaro, estou de acordo, teríamos rebeliões todos os anos, um ano da igreja, outro da nobreza, o Ministro vai mexer nos vínculos dos morgados, vai revolucionar a posse senhorial da terra, vai mandar arrancar as cepas velhas por todo o Portugal e forçar os lavradores a semearem cerais, dois milhões de cruzados, em ouro, seguem todos os anos para Inglaterra, para se pagar a farinha que comemos. (REAL, 2005a, p. 290)

A violência do ministro Carvalho e Melo é considerada por João Maria como um mal necessário em direção ao progresso e uma emancipação dos poderes vigentes em Portugal até àquele momento. Tudo é, portanto, realizado pela "boa razão do Estado" (REAL, 2005a, p. 291).

Mas Miguel Real insere nesse discurso entusiástico um elemento sutilmente satírico: os irmãos João Maria e José Maria Peixoto assumem no romance um papel muito parecido ao de Rosencrantz e Guildenstern no Hamlet de Shakespeare, os antigos amigos do príncipe da Dinamarca que se põem a serviço do novo rei para espiar Hamlet, que os deixará morrer. Rosencrantz e Guildenstern são, assim, dois idiotas a serviço do poder, que não percebem que podem ser sacrificados. Os Peixotinhos, por sua vez, aparecem como dois ingênuos, dois instrumentos nas mãos da pessoa mais influente de Portugal. Suas devoções parecem uma fórmula repetida para confirmar a posição do mais poderoso. $\mathrm{O}$ discurso que um deles faz para convencer Julinho da "boa razão" das políticas do ministro são as palavras de um bêbado num monólogo que se torna grotesco: "João Maria elevava a voz, a retórica política, empurrada pela barriga farta de ovos e presunto e pela ardência da 
aguardente na garganta, saía-lhe solta e entusiasmada”(REAL, 2005a, p. 290). O discurso mítico sobre o futuro Marquês de Pombal fica então ridiculizado pelo mecanismo de "use and abuse of history", interpretado por Linda Hutcheon como característica da "historiographic metafiction" (HUTCHEON, 1988), em que a escrita canonizada da história é posta em causa pela paródia.

A decisão de Julinho é a de não compactuar com essas ideias e voltar para o Brasil: apesar das mudanças dos últimos anos, o estilo de vida e as crenças da sociedade parecem ter continuado a existir, mudando somente na superfície:

tudo mudara em menos de dez anos, tudo ia mudando, Lisboa espraiara-se, geometrizara-se, racionalizara-se, industrializava-se, alfabetizara-se, modernizara-se. Lisboa veste outra ela, burguesa, argentária, europeia, mas, qualquer que seja a pele de que se vista, nunca deixará de ser uma cidade crente, rude e supersticiosa, a cidade de Santo António, pátria da inveja, sempre ansiando por uma elite iluminada que a venha a salvar. (REAL, 2005a, p. 316)

Como já sugerido, a escrita de Miguel Real apresenta um equilíbrio sutil. Na frase acima citada, não é possível encontrar uma referência direta à atualidade, já que as palavras são filtradas pela voz de um narrador que se refere apenas ao contexto da história em questão. Mas o jogo é delicado: o discurso sobre a construção da Comunidade Económica Europeia partilha várias características com as políticas que Miguel Real faz ressaltar na figura do ministro Carvalho e Melo e que fazem dele um mito da história de Portugal com a ideia de progresso, a necessidade de uma adesão total a um projecto nascido noutros contextos, e o favorecimento do comércio como instrumento de "boa razão" para a política. A referência a uma "elite iluminada" pode ser analisada como uma provocação ao leitor, que fica na dúvida se a confiança acrítica na participação de Portugal à CEE é, ou não, a última das contínuas ilusões que marcam a história deste país. A voz da terra resultaria ser, três anos antes do começo da crise económica, uma crítica a um processo de integração à nova ordem econômica europeia. Partindo dessa leitura tais inovações demonstram ser novas superstições que não eliminam os desníveis sociais, mas que dão à luz novas ilusões.

Pôr em evidência as ilusões que caracterizam a origem da Europa moderna, ou pelo menos as suas contradições, seria, nessa medida, pôr em questão as modalidades pelas quais o atual projecto europeu foi se instalando e ainda se legitima. 


\section{Bibliografia:}

BAUMAN, Zygmunt. Modernity and the Holocaust. Cambridge: Polity, 1989.

BAUMAN, Zygmunt. Postmodern Ethics. Oxford: Blackwell, 1993.

BUESCU, Helena Carvalhão, CORDEIRO, Gonçalo. O grande terramoto de Lisboa: ficar diferente. Lisboa: Gradiva, 2005.

DYNES, Russell R. "The Lisbon Earthquake of 1755: the first modern disaster". Braun, Theodore E. D. e Radner, John B. (cur.). The Lisbon earthquake of 1755: representations and reactions. Oxford: Voltaire Foundation, pp. 34-49, 2005.

FRANCO, José Eduardo, RITA, Annabela. O mito do Marquês de Pombal: a mitificação do primeiro-ministro de d. José pela maçonaria. Lisboa: Prefácio, 2004.

FRANÇA, José-Augusto. "Lisboa de Pombal: a grande criação do Iluminismo". Jornal de Letras, Arte e Ideias, Lisboa, 9-22 Novembro, p. 29, 2005.

HUTCHEON, Linda. A Poetics of Postmodernism: History, Theory, Fiction. London \& New York: Routledge, 1988.

ISRAEL, Jonathan, "Enlightenment! Which Enlightenment?". Jornal of the History of Ideas, University of Pennsylvania Press, Vol. 67, n. 3, p. 523-545, Jul. 2006.

LOURENÇO, Eduardo. "Nós e a Europa: Ressentimento e fascínio". Nós e a Europa: ou as duas rąões. Lisboa: Imprensa nacional-Casa da moeda, 1990.

MANERA, Enrico. Furio Jesi: Mito, violenza, memoria. Roma: Carocci, 2012.

REAL, Miguel. A Voz da terra. Porto: Quidnovi, 2005a.

REAL, Miguel. O Marquês de Pombal e a cultura portuguesa. Porto: Quidnovi, 2005b.

REAL, Miguel. "A tragédia revisitada". Jornal de Letras, artes e ideias. Lisboa, 9-22 Novembro, p. 26-28, 2005c.

REAL, Miguel, Eduardo Lourenço e a cultura portuguesa. Porto: Quidnovi, 2008.

REAL, Miguel. “A herança de Saramago”. Vértice, Lisboa, n.168, 2013.

SARAMAGO, José. A jangada de pedra. Lisboa: Caminho, 1986.

TAVARES, Rui. O Pequeno Livro do Grande Terramoto. Lisboa: Edições Tinta-da-china, 2005.

TAVARES, Urbano Sousa. "Miguel Real. Um romance convincente". Jornal de Letras, artes e ideias. Lisboa, 6-19 Dezembro, p. 42, 2006. 